Article

\title{
Development of a Novel Degradation-Controlled Magnesium-Based Regeneration Membrane for Future Guided Bone Regeneration (GBR) Therapy
}

\author{
Da-Jun Lin ${ }^{1}$, Fei-Yi Hung ${ }^{1, *}$ (D) , Hung-Pang Lee ${ }^{2}$ and Ming-Long Yeh ${ }^{2, *}$ \\ 1 Department of Materials Science and Engineering, National Cheng Kung University, Tainan 701, Taiwan; \\ larrylin111@hotmail.com \\ 2 Department of Biomedical Engineering, National Cheng Kung University, Tainan 701, Taiwan; \\ qer6322129@gmail.com \\ * Correspondence: fyhung@mail.ncku.edu.tw (F.-Y.H.); mlyeh@mail.ncku.edu.tw (M.-L.Y.); \\ Tel.: +886-06-2757575 (ext. 62950) (F.-Y.H.); +886-06-2757575 (ext. 63429) (M.-L.Y.)
}

Received: 21 September 2017; Accepted: 3 November 2017; Published: 6 November 2017

\begin{abstract}
This study aimed to develop and evaluate the ECO-friendly Mg-5Zn-0.5Zr (ECO505) alloy for application in dental-guided bone regeneration (GBR). The microstructure and surface properties of biomedical $\mathrm{Mg}$ materials greatly influence anti-corrosion performance and biocompatibility. Accordingly, for the purpose of microstructure and surface modification, heat treatments and surface coatings were chosen to provide varied functional characteristics. We developed and integrated both an optimized solution heat-treatment condition and surface fluoride coating technique to fabricate a $\mathrm{Mg}$-based regeneration membrane. The heat-treated Mg regeneration membrane (ARRm-H380) and duplex-treated regeneration membrane group (ARRm-H380-F24 h) were thoroughly investigated to characterize the mechanical properties, as well as the in vitro corrosion and in vivo degradation behaviors. Significant enhancement in ductility and corrosion resistance for the ARRm-H380 was obtained through the optimized solid-solution heat treatment; meanwhile, the corrosion resistance of ARRm-H380-F24 h showed further improvement, resulting in superior substrate integrity. In addition, the ARRm-H380 provided the proper amount of Mg-ion concentration to accelerate bone growth in the early stage (more than $80 \%$ new bone formation). From a specific biomedical application point of view, these research results point out a successful manufacturing route and suggest that the heat treatment and duplex treatment could be employed to offer custom functional regeneration membranes for different clinical patients.
\end{abstract}

Keywords: Mg alloy; regeneration membrane; guided bone regeneration; heat treatment; fluoride coating; biocompatibility

\section{Introduction}

Periodontitis is a bacterial-mediated inflammatory disease that can lead to damage of the periodontal ligament and gingival tissue, and may also cause alveolar bone resorption [1]. The prevalence of continuous periodontitis growth has been well documented in modern society [2], and in many clinical reports, delaying therapy can eventually result in tooth loss and alveolar atrophy (especially for older patients) [3]. In such cases, the defect area must first be reconstructed before artificial tooth root implantation. To this end, guided bone regeneration (GBR) procedures have been noted as a reliable periodontal regeneration and alveolar augmentation therapy, and have registered high success rates in recent years [4]. Currently, there are two material systems for GBR procedures, namely degradable and non-degradable membrane materials [5]. With degradable regeneration membranes (usually made by poly-lactic acid (PLA) or collagen sheets), secondary surgery for implant 
removal is not required; however, the low mechanical strength and stiffness do not offer sufficient structural strength. In contrast, non-degradable regeneration membranes (e.g., Ti mesh or Teflon-mesh) are the most commonly used materials; however, their use requires secondary surgery for membrane removal, which increases the risk of bacterial infection. In response to these clinical considerations, this study targeted the development of a new type of regeneration membrane that features both adequate strength and biodegradability.

Magnesium (Mg) is a promising metallic material for biomedical applications due to its unique biodegradability, satisfactory biocompatibility, and excellent biomechanical properties [6]. Moreover, $\mathrm{Mg}$ materials possess satisfactory biocompatibility and biofunctionality that can accelerate cell proliferation and wound healing $[7,8]$. Therefore, $\mathrm{Mg}$ materials can be seen as potential candidates for new types of regeneration membranes for dental GBR procedures. However, the poor anti-corrosion behaviors and rapid mechanical fading of $\mathrm{Mg}$ materials in a physiological electrolyte environment currently limit its clinical applicability [9,10]. Nevertheless, Cai et al. recently revealed that $\mathrm{Mg}-5 \mathrm{Zn}$ alloy is a good candidate for orthopedic implants with an optimal Zn alloying amount [11]. Song et al. also demonstrated that $\mathrm{Mg}-5 \mathrm{Zn}$ alloy possesses a uniform corrosion behavior and less localized corrosion incidence [12]. Moreover, several related studies have shown that properly modified (including microstructure modification and surface treatment) $\mathrm{Mg}$ implants offer stable mechanical retention with reasonable degradation rates both in vitro and in vivo [13-15]. Results from our previous works showed that heat treatment and plastic deformation procedures greatly influence the degradation behavior and biocompatibility of $\mathrm{Mg}-\mathrm{Zn}-\mathrm{Zr}$ series alloys via microstructure transformation $[7,16]$. Li et al. investigated in vitro and in vivo corrosion, as well as the mechanical properties and biocompatibility of $\mathrm{Mg}-\mathrm{Zn}-\mathrm{Zr}$ alloy; in addition, their research also indicated that the degradation behavior and bone healing behavior could be effectively improved after surface fluoride coating [17].

At present, the global demand of $\mathrm{Mg}$ materials is increasing year by year. It therefore follows that the demand will further increase once Mg-based medical devices are widely accepted in clinical practice. However, the casting procedure of $\mathrm{Mg}$ alloys always needs to use a great amount of $\mathrm{SF}_{6}$ (a potent greenhouse gas), which can accelerate global warming [18]. To mitigate this shortcoming, the $\mathrm{SF}_{6}$-applied casting procedure should be replaced by novel green ECO-casting techniques (using HFC-134a gas). In this study, to fabricate a highly functional medical device, a novel ECO-casting technique, which integrates a solid-solution heat treatment and surface treatment, was developed to produce an optimized biodegradable regeneration membrane for dental application using ECO-friendly Mg-5Zn-0.5Zr (named ECO505) alloy material.

\section{Materials and Methods}

\subsection{ECO-Casting Process and Shaping Process}

Mg-20 wt. \% Zr, 4N grade (99.99 wt. \%) pure Mg and pure Zn ingots were used for producing a Mg-5Zn-0.45Zr alloy billet. The precisely weighted raw materials were melted in a mild steel crucible using an electrical resistance furnace. During the melting and alloying process, a 20\% HFC-R134a-80\% Ar gas mixture was applied to the melt as a protection gas to prevent self-ignition [19]. The melt was held at $700{ }^{\circ} \mathrm{C}$ and stirred to homogenize the melt composition. After the melting process, the melt was cast into a preheated $\left(350^{\circ} \mathrm{C}\right)$ stainless steel mold to produce the ECO505 alloy billet (as shown in Figure 1).

Before the regeneration membrane shaping process, the cast billets were previously homogenized at $380{ }^{\circ} \mathrm{C}$ for $12 \mathrm{~h}$ and subsequently water quenched. Afterwards, the homogenized billets were directly extruded at $350{ }^{\circ} \mathrm{C}$ using a ram speed of $10 \mathrm{~mm} / \mathrm{s}$ and an extrusion ratio of 35 to form stripe extrudates. The rolling raw materials ( $40 \mathrm{~mm}$ in length, $15 \mathrm{~mm}$ in width and $4 \mathrm{~mm}$ in height) were cut from the stripe extrudates with the rolling plane parallel to the extrusion direction. During the hot-rolling process, the process conditions were fixed at the rolling strain rate of $1.98 \mathrm{~s}^{-1}$ and under $350{ }^{\circ} \mathrm{C}$, for which the reduction rate per rolling pass was $20 \%$. Furthermore, the rolled samples were 
reheated to $350{ }^{\circ} \mathrm{C}$ and kept at that temperature for $5 \mathrm{~min}$ prior to each rolling pass. The final thickness of the as-rolled ECO505 regeneration membrane (named as ARRm) samples was controlled at $0.4 \mathrm{~mm}$ (as shown in Figure 1).

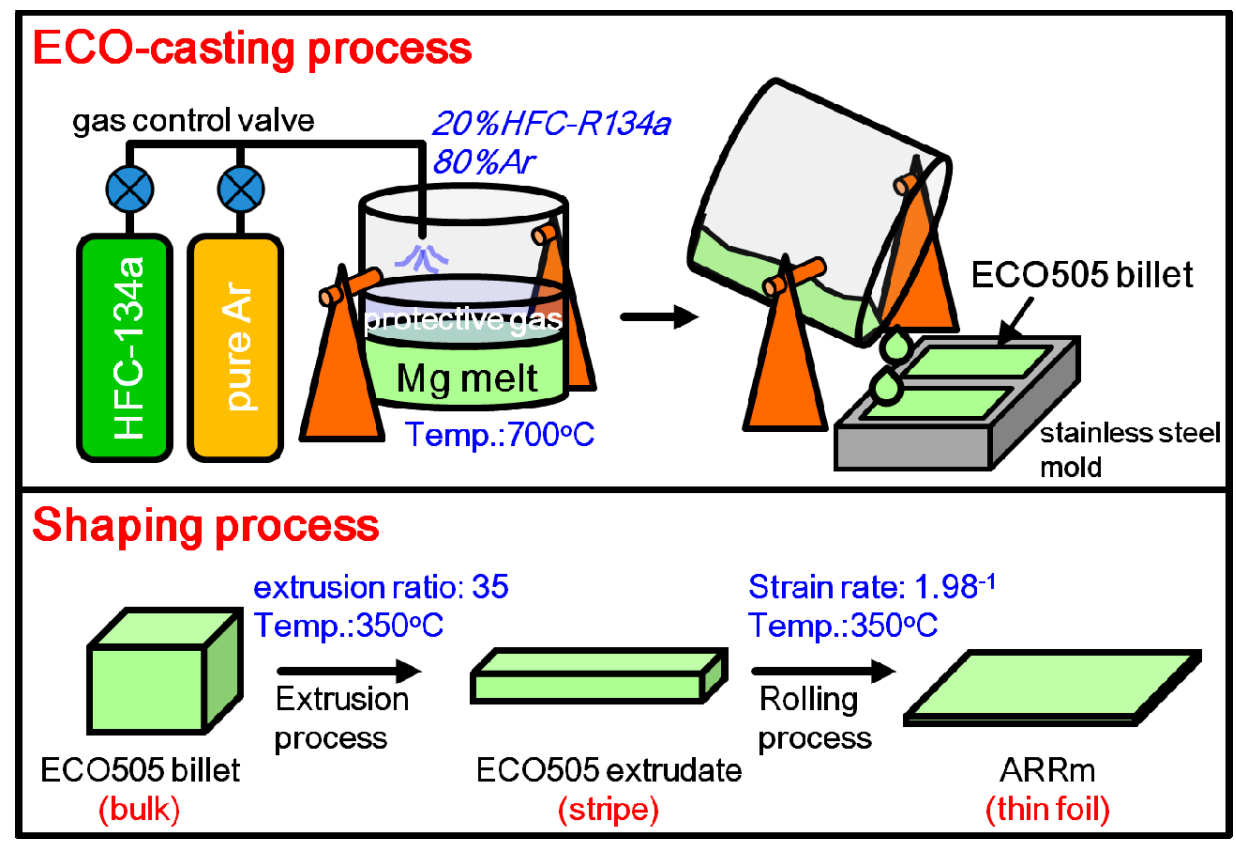

Figure 1. Schematic diagram of ECO-casting process and shaping process.

\subsection{Heat Treatment Modification}

The ARRm samples were processed into a circular thin foil (12.7 $\mathrm{mm}$ in diameter). Solution heat treatment of the ARRm samples was carried out in a tubular vacuum furnace at $380{ }^{\circ} \mathrm{C}$ for 1, 2, 4 and $10 \mathrm{~h}$, respectively. After heat treatment, the samples were water quenched at room temperature. The names for the solution heat-treated samples were assigned by heating time as follows: ARRm-380 ${ }^{\circ} \mathrm{C} \_1 \mathrm{~h}, \mathrm{ARRm}-380^{\circ} \mathrm{C} \_2 \mathrm{~h}, \mathrm{ARRm}-380^{\circ} \mathrm{C} \_4 \mathrm{~h}$ and ARRm-380 ${ }^{\circ} \mathrm{C} \_10 \mathrm{~h}$. The name of the final optimized condition was replaced by ARRm-H380 to show its representative meaning.

\subsection{Surface Fluoride Coating}

The surfaces of the ARRm and ARRm-H380 samples were coated with a protective $\mathrm{MgF}_{2}$ layer. Prior to the coating process, all samples were polished successively with 200 to 8000 grit using $\mathrm{SiC}$ sandpaper. The polished specimens were rinsed in acetone and ethanol, and subsequently dried in a stream of dry air. The fluoride conversion treatment followed the suggested procedure from a previously published report, which involved the samples being soaked in $42 \mathrm{wt}$. \% HF and

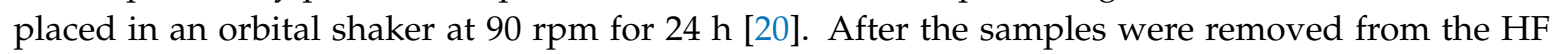
conversion bath, they were rinsed twice with absolute ethanol and dried. Names for the $\mathrm{MgF}_{2}-\mathrm{coated}$ samples were assigned according to treatment history, and hereafter referred to as ARRm-F24 h and ARRm-H380-F24 h, respectively.

\subsection{Materials Characterization}

All samples (as-cast, as-extruded and ARRm) for microstructure characterization were ground and polished to $0.05 \mu \mathrm{m}$ and finally etched by picric-acetic acid solution ( $4.2 \mathrm{~g}$ picric acid $+20 \mathrm{~mL}$ acetic acid $+80 \mathrm{~mL}$ ethanol). Optical microscopy (BX41-LED, Olympus, Tokyo, Japan) and scanning electron microscopy (JSM-6510LV, JEOL, Tokyo, Japan) with an energy dispersive spectrometer (EDS, INCA 350, Oxford Instrument, Oxford, UK) were used for microstructure characterization. The average grain 
size was determined according to the ASTM E112-96 standard. With the aim to characterize the effects of heat treatment on matrix softening, Vicker's hardness measurements (HMV-G21, Shimadzu, Kyoto, Japan) were performed on the polished surface of the heat treated specimens with different treatment conditions, for which the loaded force was $100 \mathrm{~g}$ and the holding time was $10 \mathrm{~s}$. Tensile test used a hydraulic-powered mechanical testing system (MTS-810, MTS Systems Corporation, Minneapolis, MN, USA) with a tensile speed of $1 \mathrm{~mm} / \mathrm{min}$. A typical dog-bone tensile specimen expressed with a gauge length of $20 \mathrm{~mm}$, a gauge width of $7 \mathrm{~mm}$ and a thickness of $0.4 \mathrm{~mm}$ was selected for tensile test. At least four samples are tested (Vicker's hardness and tensile test) for each group.

\subsection{In Vitro Corrosion Test}

The electrochemical corrosion mechanism and performance of the fluoride conversion coating were investigated using an electrochemical station (PARSTAT 2273, Princeton Applied Research, Oak Ridge, TN, USA). Polarization curves were measured using a classic three-electrode cell, where a saturated calomel electrode $(\mathrm{SCE},+0.242 \mathrm{~V}$ vs. SHE) constituted the reference electrode with a Pt-coated Ti mesh as the counter-electrode. The area of the working electrode exposed to the electrolyte was controlled to within $1 \mathrm{~cm}^{2}$ by a Teflon holder. The electrolyte used was revised simulated body fluid (r-SBF) solution (which per liter included $5.403 \mathrm{~g}$ of $\mathrm{NaCl}, 0.736 \mathrm{~g}$ of $\mathrm{NaHCO}_{3}, 2.036 \mathrm{~g}$ of $\mathrm{Na}_{2} \mathrm{CO}_{3}, 0.225 \mathrm{~g}$ of $\mathrm{KCl}, 0.182 \mathrm{~g}$ of $\mathrm{K}_{2} \mathrm{HPO}_{4}, 0.310 \mathrm{~g}$ of $\mathrm{MgCl}_{2} \cdot 6 \mathrm{H}_{2} \mathrm{O}, 11.928 \mathrm{~g}$ of 4-(2-hydroxyethyl)-1-piperazineethanesulfonic acid (HEPES), $0.293 \mathrm{~g}$ of $\mathrm{CaCl}_{2}$, and $0.072 \mathrm{~g}$ of $\mathrm{Na}_{2} \mathrm{SO}_{4}$ dissolved in deionized water) buffered at $\mathrm{pH}=7.4$ using $\mathrm{HEPES}$ and $\mathrm{NaOH}$, with the environmental temperature controlled at $37^{\circ} \mathrm{C}$. Prior to conducting the experiment, nitrogen gas was bubbled through the r-SBF to remove dissolved oxygen. The polarization curve was acquired with a scanning rate of $1 \mathrm{mV} \mathrm{s}^{-1}$ from $-1.8 \mathrm{~V}$ to $-0.8 \mathrm{~V}$.

To characterize the corrosion properties of the $\mathrm{Mg}$-based regeneration membrane, two immersion corrosion examinations were used in this research. Firstly, the normal immersion corrosion (un-bent/r-SBF immersion) test was employed to measure the corrosion rates, behaviors and tendencies of the specimens in r-SBF by following the principle of ASTM G31-72. The r-SBF volume to surface area ratio was fixed at $20 \mathrm{~mL} / \mathrm{cm}^{2}$. Secondly, the actual-simulated immersion corrosion (pre-bent/r-SBF immersion) test was employed to acquire the corrosion rates, behaviors and tendencies of the pre-bent specimens in r-SBF by a custom designed examination. For this examination, several PVC racks ( $1 \mathrm{~cm}$ width and $5 \mathrm{~cm}$ long) were used to act as alveolar bone, upon which the pre-bent specimens were fixed by nylon screws, as shown in Figure 2a. Then, the specimens were immersed into r-SBF. The r-SBF volume to surface area ratio of this custom designed examination was fixed at $50 \mathrm{~mL} / \mathrm{cm}^{2}$. The experiments were held for 1 week in an isothermal incubator at $37^{\circ} \mathrm{C}$. The result is the average of five samples $(n=5)$.

(a)

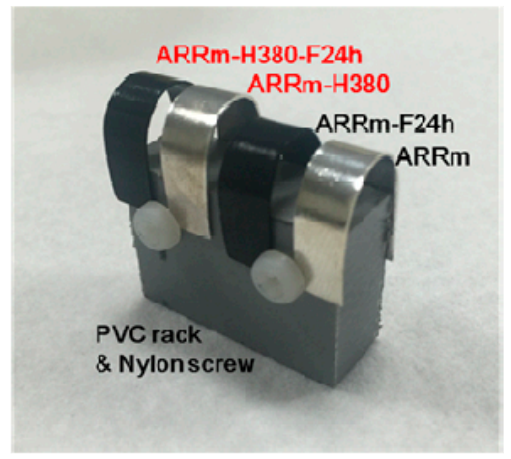

Figure 2 (b)

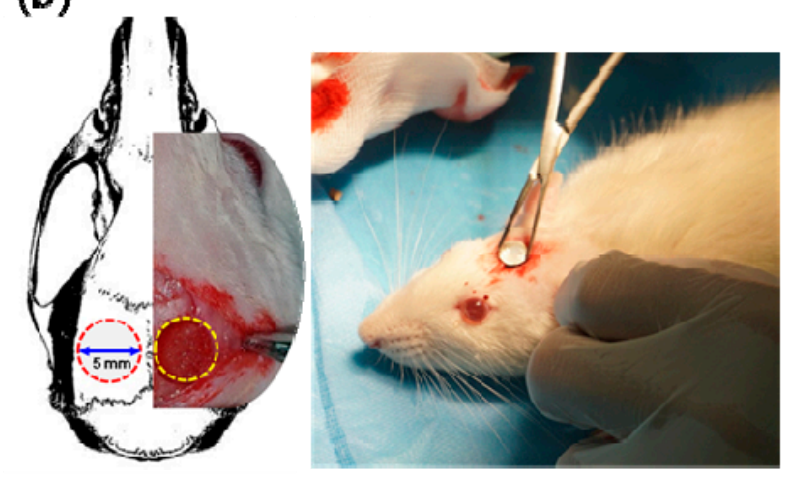

implantation model. 


\subsection{Animal Model and Cranial Implantation Experiments}

In this study, the animal experiments and surgical procedure were approved by the Institutional Animal Care and Use Committee of National Cheng Kung University (approval No. 105258). Male-controlled Sprague Dawley (SD) rats were housed in an environmentally controlled animal feeding room $\left(25 \pm 1{ }^{\circ} \mathrm{C}, 40 \sim 70 \%\right.$ humidity, with a regular $12 \mathrm{~h}$ light cycle per day) to an age of $12 \sim 14$ weeks. All SD rats were randomly assigned to testing groups prior to surgery. General anesthesia was administered via an intra-abdominal injection of Zoletil 50 (Virbac, Carros, France) and Xylazine (Panion and BF Biotech Inc., Taipei, Taiwan) mixture $(0.2 \mathrm{mg} / 100 \mathrm{~g}$ of Zoletil 50 and $0.5 \mathrm{mg} / 100 \mathrm{~g}$ of Xylazine); then, local infiltration anesthesia (xylocaine, $0.2 \mathrm{~mL}$ for each surgical incision) was performed at the surgical sites before surgery. An incision along the periphery of the skull was created to peel back to the anterior portion of the skull. Two $5 \mathrm{~mm}$ critical size defect (CSD) were drilled in the calvarial bone using a trephine bur and low speed handpiece (as shown in Figure 2b). While drilling the cranial bone, sterilized saline was continuously injected to cool the drilling heat. The defects were covered with the regeneration membrane (a circular foil $7 \mathrm{~mm}$ in diameter and $0.4 \mathrm{~mm}$ thick) made by ECO505 raw material. Control and experimental groups (ARRm-H380 and ARRm-H380-F24 h) were employed to realize the applicability and performance of the regeneration membranes. After surgery, the wounds were closed by $5-0$ non-absorbable silk sutures and antibiotics applied to prevent wound infection. At least four SD rats are examined for each group and time point $(n=4)$.

\subsection{Micro-CT Analysis and 3D Image Reconstruction}

To obtain both qualitative and quantitative data of the bone regeneration level within the CSD, a $\mu$-CT (Skyscan 1076, Kontich, Belgium) was used to scan the cranial bone. The sham, ARRm-H380 and ARRm-H380-F24 h groups were measured at 4-week and 12-week time points. The voltage and $\mathrm{X}$-ray current were controlled at $90 \mathrm{kV}$ and $110 \mu \mathrm{A}$, respectively. The examined cranial bones and ECO505 regeneration membranes were scanned through a $360^{\circ}$ rotation angle, with a rotation interval of $1^{\circ}$ and pixel size of $18 \mu \mathrm{m}$ resolution. From the data measurement with SkyScan software (Version 1.4.4, Kontich, Belgium), a cylindrical region of interest (ROI) $5 \mathrm{~mm}$ in diameter within the CSD site was selected for analysis. The volume and diameter of the bone growth were measured as the new bone volume fraction (\%). The scanned cranial bone data were then reconstructed by Mimics software (Version 4.0, Materialise NV, Leuven, Belgium) to obtain high-quality 3D reconstructions. For clear identification, the original cranial bone and new bone were colored gray and light blue, respectively.

\subsection{Statistical Analysis}

The results of mechanical and in vivo implantation experiments are given as the mean viability value \pm standard deviation. Analysis of one-way variance (ANOVA) was conducted to evaluate the statistical significance of differences. Differences at $p \leq 0.05$ were considered to be statistically significant.

\section{Results and Discussion}

\subsection{Metallographic and Microstructure Observation}

Figure 3 presents the optical micrographs of the as-cast, as-homogenized, as-extruded and as-rolled specimens. For the ECO505 billet, abundant $\mathrm{MgZn}_{2}$ particles (the main secondary phase in $\mathrm{Mg}-\mathrm{Zn}-\mathrm{Zr}$ alloy) distributed along the grain boundary can be seen. These brittle secondary phases might affect the hot-working behavior of the Mg alloy. Prasad et al. suggested that applying a homogenization heat treatment can dissolve the intermetallic particles and improve the hot workability [21]. In the present study, after a homogenization treatment at $380{ }^{\circ} \mathrm{C}$ for $12 \mathrm{~h}$, most of the $\mathrm{MgZn}_{2}$ phases were dissolved into the $\mathrm{Mg}$ matrix. The microstructure of the homogenized specimen was characterized as equiaxed grains with an average grain size of about $90 \mu \mathrm{m}$. Figure $3 \mathrm{~d}$ shows a typical extrusion feature, in which dynamic recrystallization (DRX) grains, with an average grain-size 
of about $15 \mu \mathrm{m}$, can be observed in the matrix. Figure 3e,f show macrograph and optical images of the ARRm. With respect to the macrograph, the ARRm showed no cracks, voids or severe-edge cracking. Its microstructure was fully evolved to a fine DRX microstructure without twins or other harmful defects, the average grain size of which was around $4.8 \mu \mathrm{m}$. The alloying elemental compositions of the ARRm are presented in Table 1. As seen, ARRm contains low amounts of noble impurities (such as $\mathrm{Fe}, \mathrm{Cr}, \mathrm{Ni}, \mathrm{Cu}$ ) and shows an acceptable level, indicating that the metallurgy and plastic deformation process in this work are feasible.

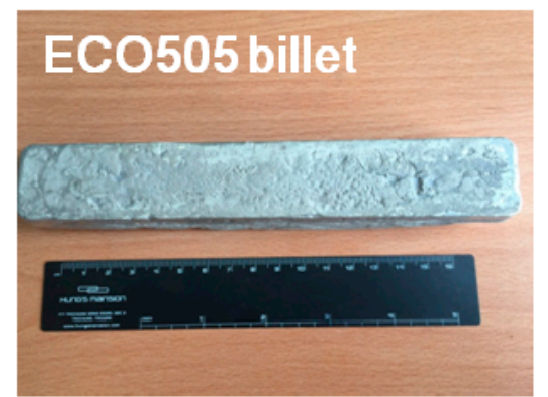

(a)

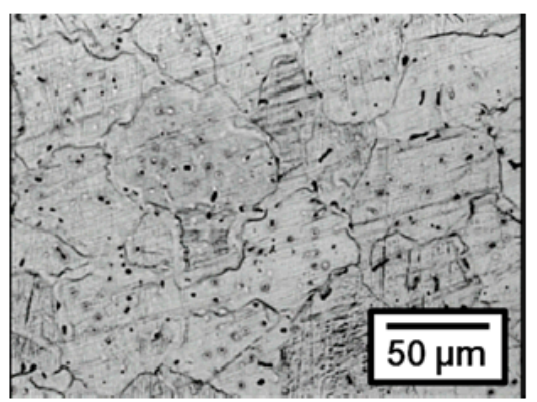

(c)

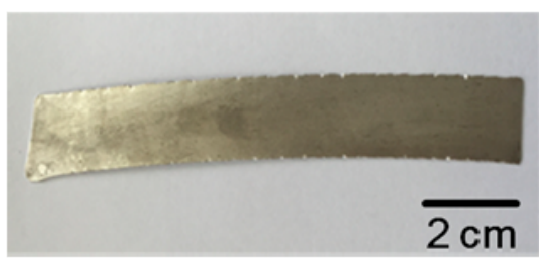

(e)

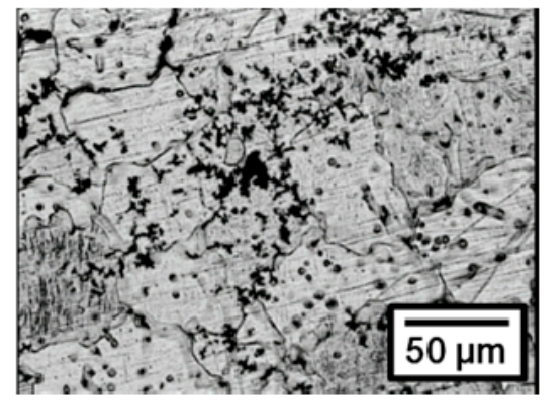

(b)

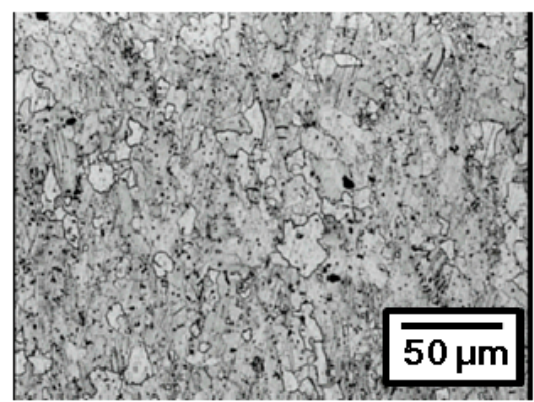

(d)

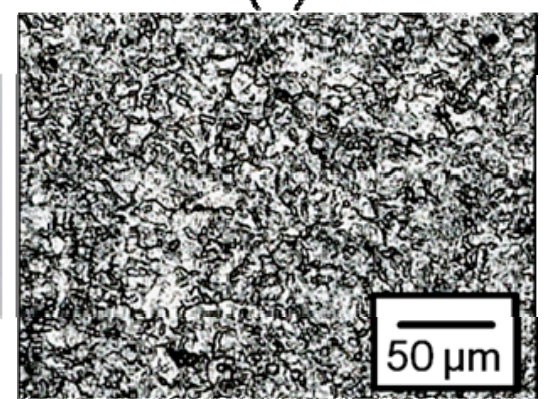

(f)

Figure 3. Typical macrograph and/or microstructures of each group: (a) macrograph of ECO505 billet; (b) microstructure of as-cast ECO505; (c) microstructure of as-homogenized ECO505 billet; (d) microstructure of as-extruded ECO505; (e,f) macrograph and microstructure of as-rolled ECO505 (named as ARRm).

Table 1. Elemental composition of ECO505 made regeneration membrane (unit: wt. \%).

\begin{tabular}{ccccccccc}
\hline Group & Zn & Zr & Fe & Cr & Ni & Mn & Cu & Mg \\
\hline ECO505 & 5.02 & 0.48 & 0.0012 & 0.0010 & 0.0023 & 0.0102 & N.D. & Bal. \\
\hline
\end{tabular}




\subsection{Solid-Solution Heat Treatment Modification and Mechanical Properties}

Figure 4 shows the hardness variation curves of the ARRm samples isothermally heat treated at $340,360,380,400$ and $420{ }^{\circ} \mathrm{C}$ for $1 \mathrm{~h}$. For the specimens heat treated at $360{ }^{\circ} \mathrm{C}$, the hardness value slightly decreased to $85 \mathrm{HV}$, which indicates insufficient solid solution efficiency. The hardness value decreased with increasing heat treatment temperature, particularly for specimens heat treated at temperatures higher than $380{ }^{\circ} \mathrm{C}$. For the treatment temperature of $380{ }^{\circ} \mathrm{C}$, the matrix was significantly softened ( $65 \mathrm{HV}$ ) than $340^{\circ} \mathrm{C}$ and $360^{\circ} \mathrm{C}$ treated groups. This phenomenon also means that the brittle secondary phases can be easily dissolved at $380^{\circ} \mathrm{C}$; therefore, we selected the temperature control of $380{ }^{\circ} \mathrm{C}$ for the ARRm heat-treatment process.

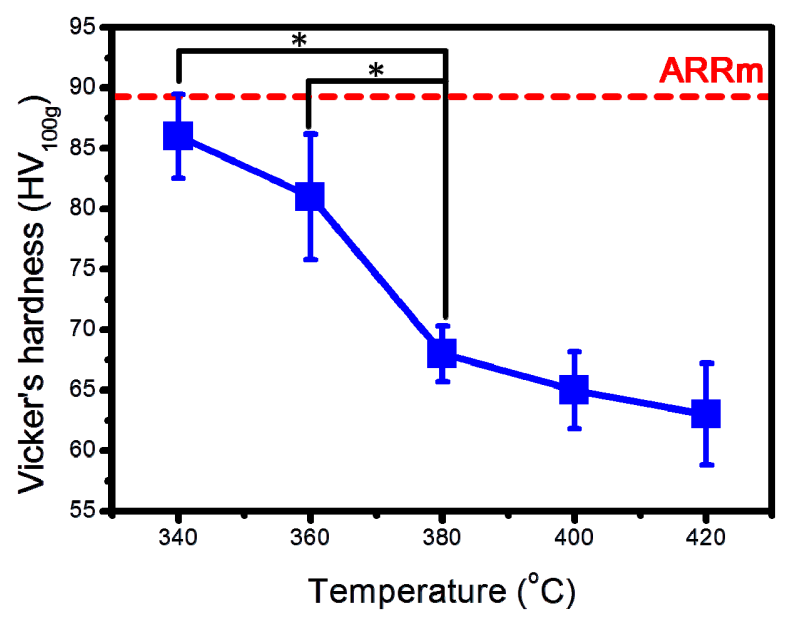

Figure 4. Vicker's hardness variation curves of different heat treatment temperature. (Data presented as mean $\pm \mathrm{SD}, n=4$ and analyzed using a one-way ANOVA, ${ }^{*} p<0.05$ ) (red dash line: the Vicker's hardness of un-solution heat treated specimen).

Figure 5 shows the microstructure evolution of ARRm isothermally heat treated at $380{ }^{\circ} \mathrm{C}$ for $1 \mathrm{~h}$, $2 \mathrm{~h}, 4 \mathrm{~h}$ and $10 \mathrm{~h}$, the characteristics of which were used to determine the optimum heat treatment time. Both the ARRm-380 ${ }^{\circ} \mathrm{C} \_1 \mathrm{~h}$ and ARRm-380 ${ }^{\circ} \mathrm{C} \_2 \mathrm{~h}$ featured many fine recrystallized grains, revealing that the fully recovered matrices had equiaxed grains with an average grain size of $5.6 \mu \mathrm{m}$ and $7.8 \mu \mathrm{m}$, respectively. The average grain sizes of ARRm-380 ${ }^{\circ} \mathrm{C} \_4 \mathrm{~h}$ and ARRm-380 ${ }^{\circ} \mathrm{C} \_10 \mathrm{~h}$ significantly grew to $18 \mu \mathrm{m}$ and $26 \mu \mathrm{m}$, respectively. Notably, the tensile properties of ARRm-380 ${ }^{\circ} \mathrm{C} \_1 \mathrm{~h}$ and ARRm-380 ${ }^{\circ} \mathrm{C} \_2 \mathrm{~h}$ showed an obvious improvement in elongation (see Figure 5e and Table 2 ). According to many previous reports, this improvement is related to the grain boundary sliding (GBS) phenomenon. GBS always occurs in fine-grained microstructures with a grain size smaller than $10 \mu \mathrm{m}$ [22]. With further increases in treatment time, the time variation significantly altered the microstructure and tensile elongation. The tensile results clearly indicate that the mechanical behavior of ARRm improved with increases in the $380{ }^{\circ} \mathrm{C}$ heating duration until $2 \mathrm{~h}$. Prolonging the heating duration of the ARRm heat treatment beyond $4 \mathrm{~h}$ led to a serious drop in elongation and yield strength behavior. Obviously, the specimens heat treated at $380{ }^{\circ} \mathrm{C}$ for $4 \mathrm{~h}$ and $10 \mathrm{~h}$ had lower yield strengths (189 MPa and $179 \mathrm{MPa}$, respectively) and elongations (11.2\% and $11.1 \%$, respectively) and displayed the overheating condition, as evidenced by their big grain sizes not being able to trigger GBS. Considering the application requirements, the elongation of the regeneration membrane must be optimized for the clinical pre-bending procedure. In the present cases, the ARRm-380 ${ }^{\circ} \mathrm{C} \_\mathrm{h}$ specimen not only maintained a small grain size, but the brittle $\mathrm{MgZn} 2$ particles also dissolved, yielding a synergistic effect that provided the best elongation of $20.2 \%$. Therefore, the heat-treatment parameter of $380^{\circ} \mathrm{C}$ for $2 \mathrm{~h}$ can be considered as the optimal condition for ARRm, and was named ARRm-H380 to show its representative meaning. 
Table 2. Mechanical parameter results of the tensile test (Data presented as mean $\pm \mathrm{SD}, n=4$ ).

\begin{tabular}{cccccc}
\hline Parameter & ARRm & ARRm-380 ${ }^{\circ} \mathbf{C} \_\mathbf{1 ~ h}$ & ARRm-380 ${ }^{\circ} \mathbf{C} \_\mathbf{2} \mathbf{h}$ & ARRm-380 ${ }^{\circ} \mathbf{C} \_\mathbf{4 h}$ & ARRm-380 ${ }^{\circ} \mathbf{C} \_\mathbf{1 0 ~} \mathbf{~}$ \\
\hline UTS (MPa) & $268 \pm 12$ & $251 \pm 9$ & $256 \pm 5$ & $224 \pm 8$ & $210 \pm 5$ \\
YS (MPa) & $248 \pm 8$ & $207 \pm 7$ & $200 \pm 6$ & $189 \pm 6$ & $179 \pm 3$ \\
EL. $(\%)$ & $8.5 \pm 0.4$ & $19.1 \pm 0.6$ & $20.2 \pm 0.4$ & $11.2 \pm 0.5$ & $11.1 \pm 0.3$ \\
\hline
\end{tabular}

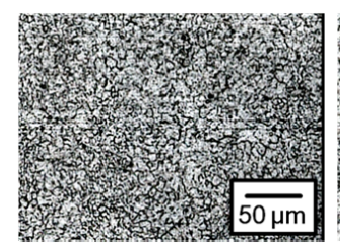

(a)

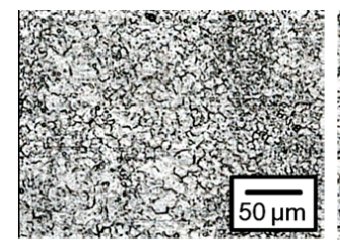

(c)

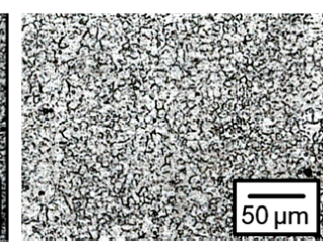

(b)

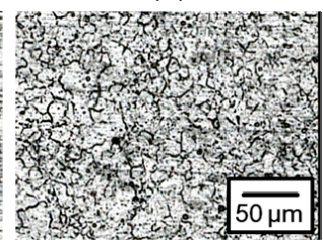

(d)

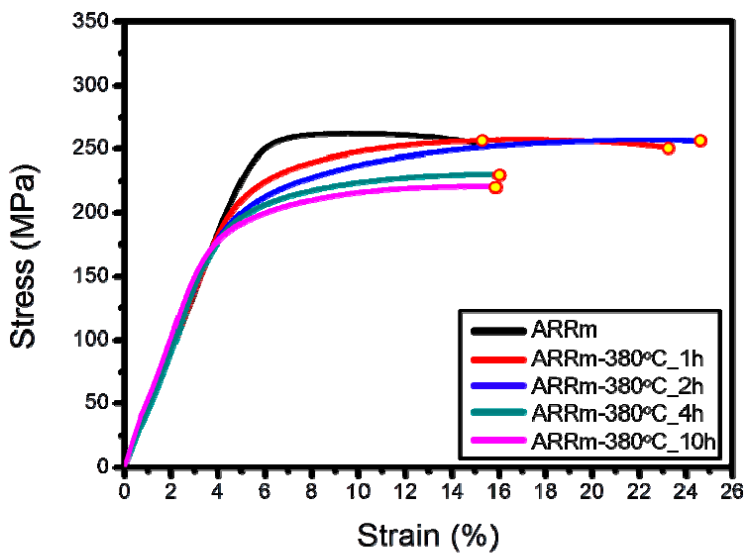

(e)

Figure 5. Typical microstructures and tensile stress-strain curves of each groups: (a) ARRm- $380{ }^{\circ} \mathrm{C} \_1 \mathrm{~h}$; (b) ARRm-380 ${ }^{\circ} \mathrm{C} \_2 \mathrm{~h}$; (c) ARRm-380 ${ }^{\circ} \mathrm{C} \_4 \mathrm{~h}$; (d) ARRm-380 ${ }^{\circ} \mathrm{C} \_10 \mathrm{~h}$, (e) stress-strain curves

\subsection{Effect of Solid-Solution Treatment and Fluoride Coating on Anti-Corrosion Ability of $\mathrm{Mg}$ Regeneration Membrane}

Figure $6 \mathrm{a}, \mathrm{b}$ show the surface morphologies of the fluoride coatings deposited on the ARRm and ARRm-H380 substrate (named ARRm-F24 $\mathrm{h}$ and ARRm-H380-F24 h, respectively). The coatings on both surfaces were neat and clean, without obvious coating defects or particle contaminants. The growth reactions of the fluoride conversion coating on the magnesium surface are described in the following:

$$
\begin{gathered}
\mathrm{Mg} \rightarrow \mathrm{Mg}^{2+}+2 \mathrm{e}^{-} \\
2 \mathrm{H}_{2} \mathrm{O}+2 \mathrm{e}^{-} \rightarrow \mathrm{H}_{2}+2 \mathrm{OH}^{-} \\
\mathrm{Mg}^{2+}+2 \mathrm{OH}^{-} \rightarrow \mathrm{Mg}(\mathrm{OH})_{2} \downarrow, \Delta \mathrm{G}=-64.51 \mathrm{~kJ} \\
\mathrm{Mg}(\mathrm{OH})_{2}+2 \mathrm{HF} \rightarrow 2 \mathrm{H}_{2} \mathrm{O}+\mathrm{MgF}_{2} \downarrow, \Delta G=-232.14 \mathrm{~kJ}
\end{gathered}
$$

The EDS spectrums of the ARRm-F24 $\mathrm{h}$ and ARRm-H380-F24 $\mathrm{h}$ specimen confirm the presence of the $\mathrm{MgF}_{2}$ on the surface, moreover, the fluorine amount of ARRm-H380-F24 h is significantly higher 
than ARRm-F24 h. ARRm-F24 h possessed only a $1.6 \mu \mathrm{m}$ fluoride layer, while ARRm-H380-F24 h possessed a $2.3 \mu \mathrm{m}$ fluoride layer, as shown in Figure 6e,f, respectively. According to our previous work, the fluoride coating of the $\mathrm{Mg}-\mathrm{Zn}-\mathrm{Zr}$ series alloy is composed of nano- $\mathrm{MgF}_{2}$ and $\mathrm{MgZn} 2$, with the distribution and homogeneity of the latter playing a key role in the coating formation mechanism [20]. Interestingly, the heat-treated specimens offered a 1.44-fold higher coating conversion efficiency, and consequently obtained a thicker coating structure than the non-heat-treated specimens. Generally speaking, a thick and dense coating offers better anti-corrosion performance.

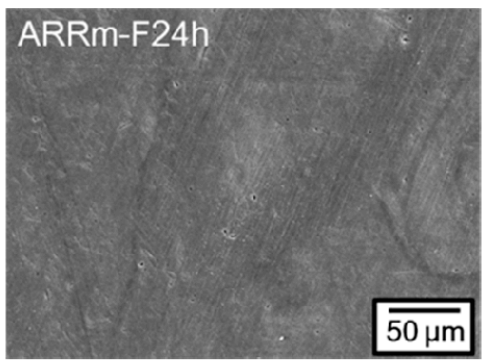

(a)

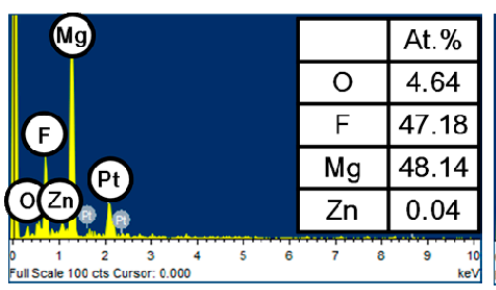

(c)

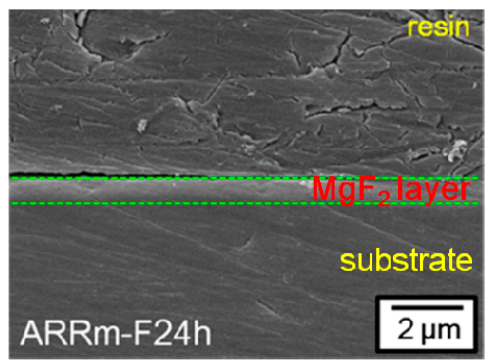

(e)

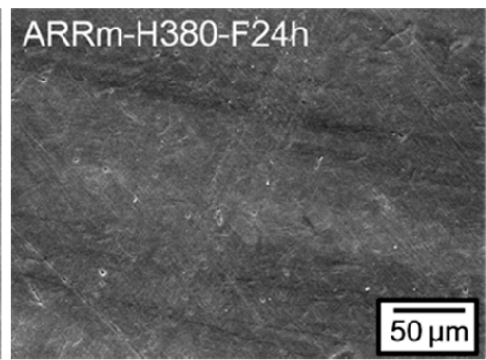

(b)

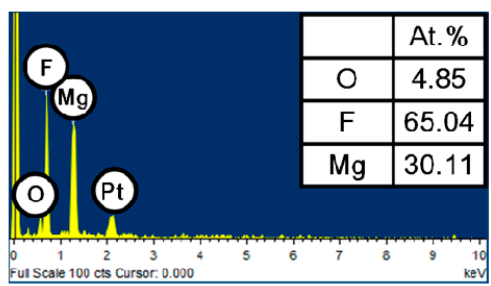

(d)

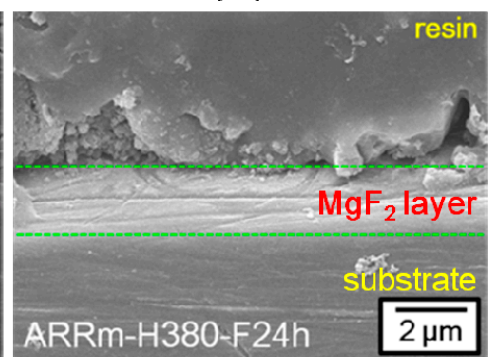

(f)

Figure 6. Surface morphologies, elemental analysis and cross-section profiles of the fluoride coated surfaces: (a) ARRm-F24 h surface; (b) ARRm-H380-F24 h surface; (c) EDS spectrum acquired from ARRm-F24 h surface; (d) EDS spectrum acquired from ARRm-H380-F24 h surface; (e) cross-section profile of ARRm-F24 h; (f) cross-section profile of ARRm-H380-F24 h.

In-vitro electrochemical polarization tests are commonly used to evaluate the corrosion resistance of biodegradable metals. For the electrochemical reaction of the $\mathrm{Mg}$ alloy, the cathodic reaction mentioned above (Equation (2)) is the water-reduction reaction, which is also closely related to the driving force of hydrogen gas evolution; meanwhile, the anodic reaction represents the oxidation driving force of the $\alpha-\mathrm{Mg}$ matrix (Equation (1)). Figure 7 shows the typical polarization curves of each experimental group in the r-SBF solution at $37^{\circ} \mathrm{C}$. The corrosion current density $\left(I_{\text {corr }}\right)$ is the most important electrochemical parameter, and is often used to calculate polarization resistance $\left(R_{\mathrm{p}}\right)$ [23]. $I_{\text {corr }}$ can be derived via the intersection point of $E_{\text {corr }}$ and the cathodic extrapolation line. Thereafter, $R_{\mathrm{p}}$ can be calculated using the Stern-Geary equation, the results of which are listed in Table 3.

Among the ARRm, ARRm-F24 h, ARRm-H380 and ARRm-H380-F24 h groups, the ARRm unmodified group showed the highest $I_{\text {corr }}$ and lowest $R_{\mathrm{p}}$ of $31.6 \mu \mathrm{A} / \mathrm{cm}^{2}$ and $1046 \Omega \cdot \mathrm{cm}^{2}$, respectively, 
which indicates that it might encounter severe oxidation and corrosion in a physiological electrolytic environment. After solid-solution heat treatment, the $\mathrm{MgZn}_{2}$ phases decomposed and dissolved into the $\alpha$-Mg matrix of ARRm-H380 (fewer micro-galvanic couples), resulting in a lower $I_{\text {corr }}(21.2$ $\mu \mathrm{A} / \mathrm{cm}^{2}$ ) than ARRm. Moreover, the significant change in current slope suggests that the ARRm-H380 microstructures had the passivation behavior, which indicates that a protective oxide film formed on the surface [24]. This protective oxide film can inhibit aggressive ions from penetrating and reacting with the inner metal surface, thereby reducing the risk of forming hydrogen cavities and releasing highly-concentrated alkali ions [25]. Both the cathodic and anodic current densities were significantly reduced in the presence of the $\mathrm{MgF}_{2}$ coating; in particular, ARRm-H380-F24 h offered the highest corrosion resistance and lowest anodic current density, and featured a wide passivation window $\left(E_{\text {break }}\right.$ $\left.-E_{\text {corr }}\right)$, indicating that the solid-solution heat treatment could further trigger better coating quality, performance and the overall anti-corrosion ability.

$$
R_{\mathrm{p}}=\frac{\beta_{\mathrm{a}} \beta_{\mathrm{c}}}{2.303\left(\beta_{\mathrm{a}}+\beta_{\mathrm{c}}\right) I_{\mathrm{corr}}}
$$

where $I_{\text {corr }}$ is the corrosion current density, while $\beta_{\mathrm{a}}$ and $\beta_{\mathrm{c}}$ are the anodic and cathodic slopes, respectively, as obtained from the Tafel region.

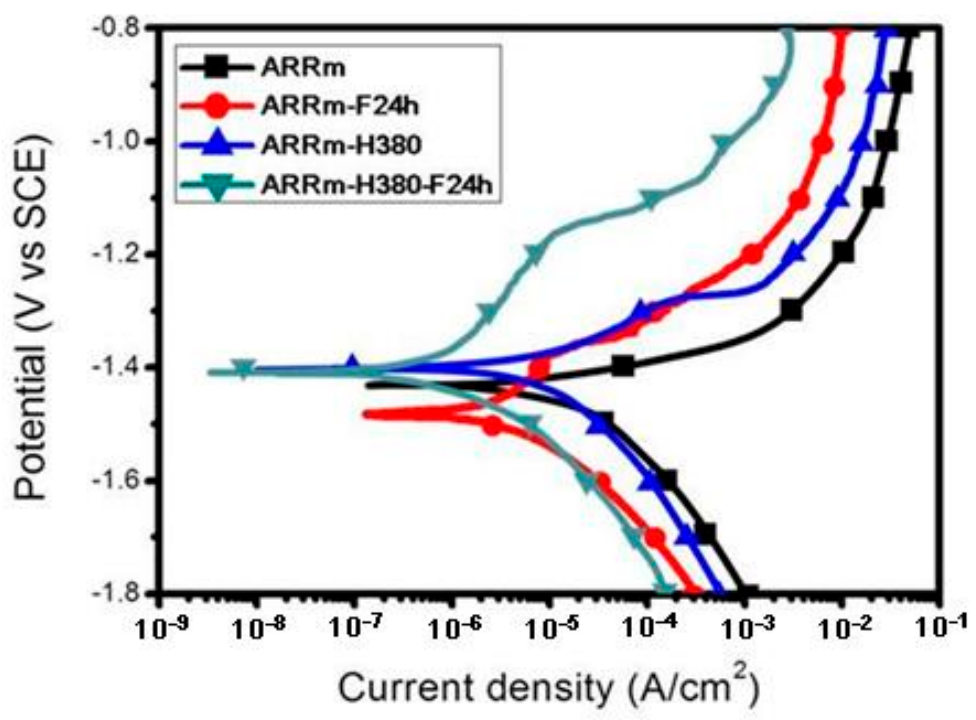

Figure 7. Electrochemical polarization curves obtained in r-SBF solution at $37^{\circ} \mathrm{C}$.

In our previous work, a duplex modified (microstructure modified and surface coated) $\mathrm{Mg}-\mathrm{Zn}-\mathrm{Zr}$ alloy was developed [20]. Although this material exhibited improved anti-corrosion behavior, the importance of the solid-solution heat treatment for fluoride conversion has not been discussed. To further understand the effect of pre-solid-solution heat treatment, the protection efficiency percentage ( $\mathrm{PE} \%$ ) is employed to elucidate the importance and contribution of this novel fabrication process.

$$
\mathrm{PE}(\%)=\frac{I_{\text {corr,sub }}-I_{\text {corr, }, \mathrm{MgF}_{2}}}{I_{\text {corr }, \text { sub }}} \times 100 \%
$$

The PE value of the fluoride coating grown on the ARRm substrate was found to be smaller $(\sim 80.3 \%)$ than that of the ARRm-H380 substrate ( 93.8\%); this may be due to the latter having superior coating homogeneity and a thicker coating. It is worth noting that the solid-solution heat treatment can balance the potential difference between the $\mathrm{MgZn}_{2}$ particles and $\mathrm{Mg}$ matrix. Moreover, owing to hydrogen gas evolution usually occurring at the micro-cathode site, the solid-solution heat treatment can also prevent the formation of a coating-depletion region on un-dissolved $\mathrm{MgZn}_{2}$ particles, resulting in higher coating efficiency and protection ability (as shown in Figures 6 and 7). 
Table 3. The resultant electrochemical polarization parameters.

\begin{tabular}{ccccccc}
\hline Group & $E_{\text {corr }}(\mathbf{V})$ & $\boldsymbol{I}_{\text {corr }}\left(\mu \mathrm{AA} / \mathbf{c m}^{2}\right)$ & $\beta_{\text {cathodic }}(\mathrm{V} / \mathrm{dec})$ & $\beta_{\text {anodic }}(\mathrm{V} / \mathbf{d e c})$ & $\boldsymbol{R}_{\mathbf{p}}\left(\boldsymbol{\Omega} \cdot \mathbf{c m}^{2}\right)$ & PE $(\%)$ \\
\hline ARRm & -1.44 & 31.6 & 0.32 & 0.10 & 1046 & - \\
ARRm-F24 h & -1.48 & 6.2 & 0.25 & 0.64 & 12,590 & 80.3 \\
ARRm-H380 & -1.40 & 21.2 & 0.23 & 0.16 & 1932 & - \\
ARRm-H380-F24h & -1.40 & 1.3 & 0.25 & 0.53 & 56,739 & 93.8 \\
\hline
\end{tabular}

\subsection{Effect of Clinical Pre-Bending Procedure on Corrosion Rate and Behavior of Mg Regeneration Membrane}

Considering the practical application of the dental GBR procedure, dentists need to bend (inducing strain and residual stress) the regeneration membrane to fit the alveolar ridge [5]. However, Mg-based alloys generally have a known issue, namely the stress-corrosion cracking (SCC) phenomenon, which can accelerate localized corrosion and further cause early failure of the materials [26]. Therefore, the additional effect of bending residual stress on $\mathrm{Mg}$ regeneration membranes must be considered and examined before clinical trial. To realize the effect of bending-corrosion behavior, un-bent/r-SBF immersion and pre-bent/r-SBF immersion experiments are discussed in the following.

The un-bent/immersion experiment was carried out at $37^{\circ} \mathrm{C}$ in r-SBF for 1,2 and 4 weeks. Figure 8a shows the corrosion rate data calculated from the normal/immersion test. During the testing period, the corrosion rates of the modified samples were significantly higher than those of the unmodified samples, the corrosion-trend sequence of which from fast to slow corrosion is: ARRm > ARRm-H380 > ARRm-F24 h > ARRm-H380-F24 h. In addition, the corrosion trends of the immersion and electrochemical tests were identical. Figure $8 \mathrm{~b}$ shows typical corroded surfaces of the different samples tested in r-SBF. The surface corrosion morphologies of the ARRm-H380 and ARRm-H380-F24 h specimens after 1, 3 and 7 days immersion shows the most homogeneous corrosion morphology. By contrast, localized corrosion, characterized by severe oxidation from the surface to the interior of the matrix, can be observed in the ARRm and ARRm-F24 h samples.

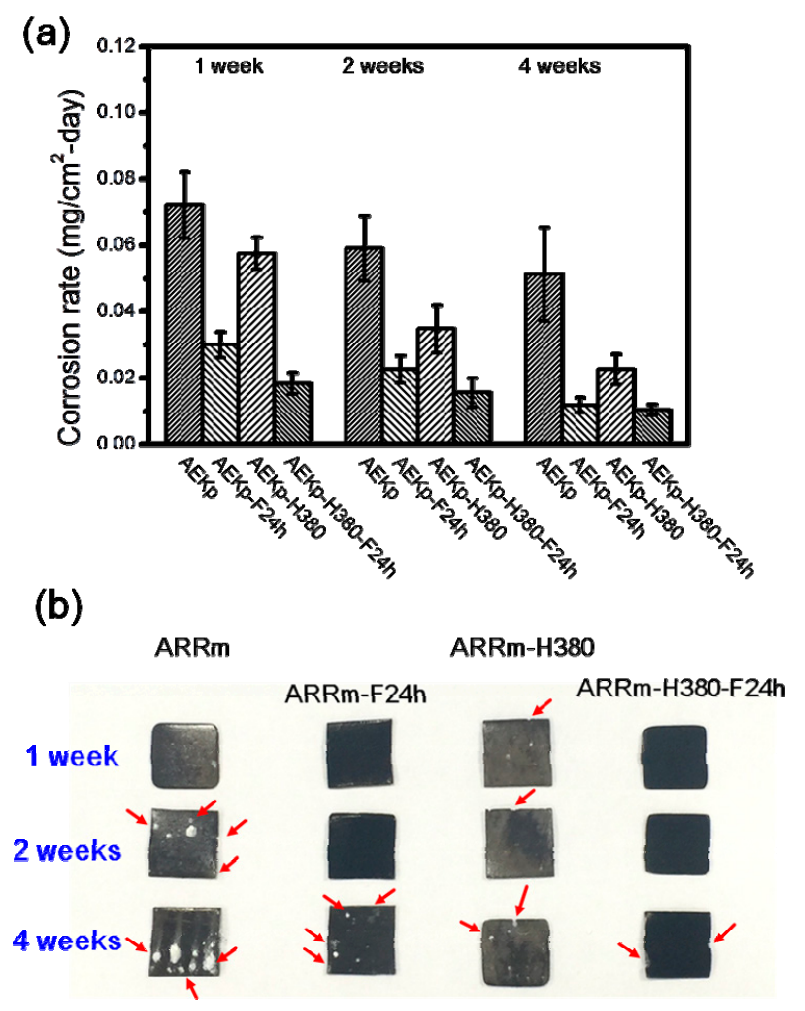

Figure 8. (a) Corrosion rates calculated from immersion test; (b) corrosion macrograph (red arrow: the location of corrosion pits). 
Figure 9 presents the corrosion macrograph and micrographs of pre-bent/r-SBF immersion specimens. There are two regions of note on the pre-bent specimens. Firstly, the top surface of the strained area is where large tensile stress is located. Only the ARRm specimen displays poor anti-stress corrosion performance, as compared with the other three specimens. Secondly, due to the heterogeneous contact interface of the nylon screw fixation site, crevice corrosion might be triggered. According to related reports, Ghali et al. stated that crevice corrosion could be initiated due to the different hydrolysis rates between the heterogeneous contact interface of $\mathrm{Mg}$ alloys. Accordingly, the formation of $\mathrm{Mg}(\mathrm{OH})_{2}$ could affect the corrosion driving force between the $\mathrm{Mg}$ regeneration membrane/screw interface in the crevices [27]. As seen in Figure 9a, the screw fixation interface of the ARRm, ARRm-F24 h, and ARRm-H380 specimens display severe crevice corrosion and accumulation of corrosion-product morphologies; however, the corrosion damage of the heat-treated sample (ARRm-H380) was clearly less than that of the ARRm and ARRm-F24 $\mathrm{h}$ samples. Notably, ARRm-H380-F24 h showed a satisfactory crevice corrosion-resistant behavior without significant corrosion damage, confirming that the solid-solution heat treatment can improve crevice-corrosion resistance.

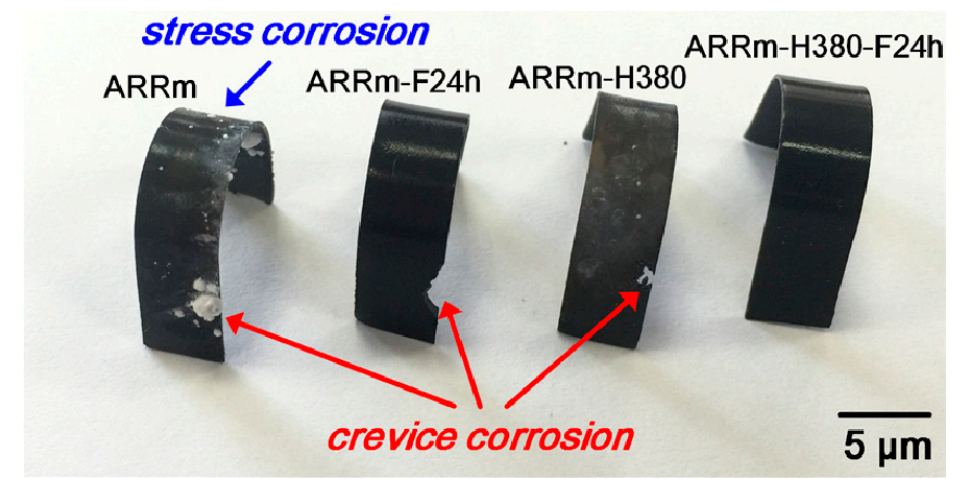

(a)

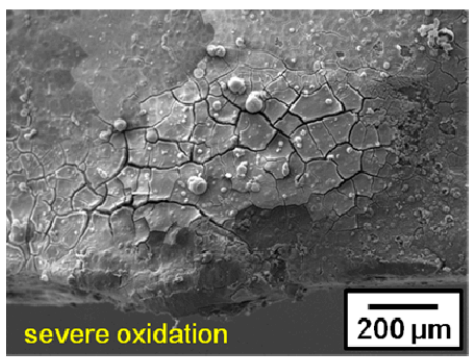

(b)

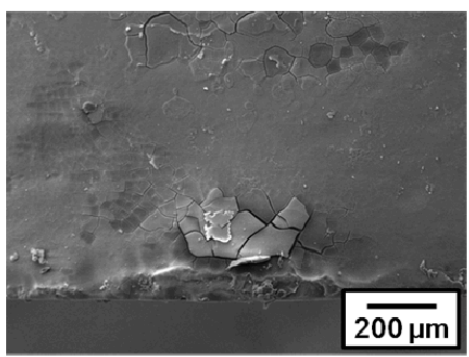

(d)

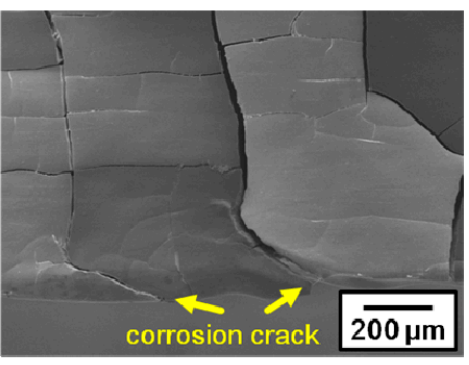

(c)

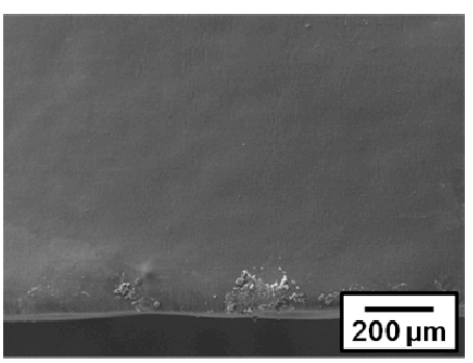

(e)

Figure 9. The pre-bent/immersion test examined specimens: (a) macrograph; and micrograph of (b) ARRm; (c) ARRm-F24 h; (d) ARRm-H380; (e) ARRm-H380-F24 h.

After immersion in r-SBF for 1 week, the corrosion trends from the un-bent/immersion and pre-bent/immersion tests were the same (Figure 10); however, the corrosion rates calculated from the 
pre-bent/immersion test were higher than those calculated from un-bent/immersion test. This can be logically explained by the effects of the bending residual stress and heterogeneous interface (screw fixation site), which can further accelerate the corrosion reaction.

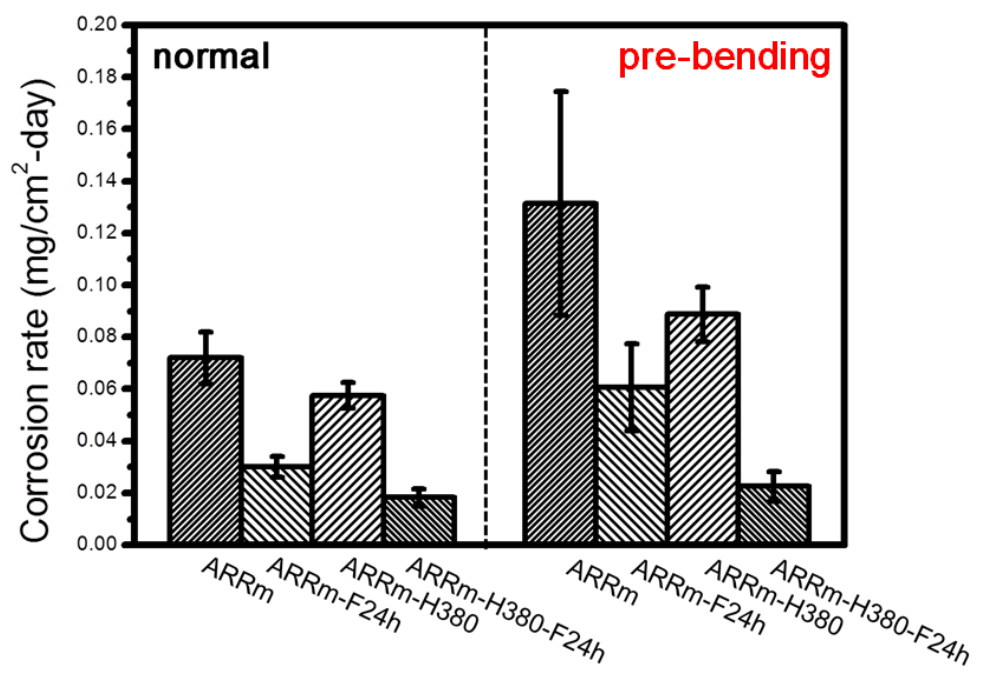

Figure 10. Corrosion rates calculated from un-bent/immersion (marked as normal) and pre-bent/immersion test (marked as pre-bending).

Relatively higher degradation rates for the non-coated series groups (namely ARRm and ARRm-H380) were found, which suffered aggressive corrosion by chlorine and/or other reactive ions. By comparison, after the H380 treatment, the specimens showed relatively lighter corrosion than the untreated ARRm. Moreover, the results also indicate that the fluoride coatings formed on the H380-treated specimens are denser and have fewer defects, thereby providing lower corrosion rates. As such, it is of great significance to reduce the secondary phase of the $\mathrm{Mg}$ alloy substrate (the contribution of H380), in order to improve the coating integrity and its protection against corrosion. Song et al. reported similar outcomes, where pre-solid-solution treatment could effectively improve the coating integrity of a Mg-2Zn-Mn-Ca-Ce alloy [28]. Considering that the performance of the heat-treated samples was superior, the following animal experiments only used the ARRm-H380 and ARRm-H380-F24 $\mathrm{h}$ alloys to examine the practicability.

\subsection{In Vivo Degradation and Bone Healing Situation}

During the implantation period, all experimental rats showed good health and wound healing until the end of this research. There were no severe side effects, obvious weight reduction, allergies, rejection and postoperative infection in the rats. Figure 11 shows the hydrogen accumulation phenomenon in the ARRm-H380 group after 4 weeks and 12 weeks of implantation. As can be seen, the photograph shows that ARRm-H380 produced a subcutaneous hydrogen gas cavity, indicating that the degradation amount of ARRm-H380-F24 h was significantly lower than ARRm-H380. The generation of hydrogen gas cavity is inevitable, due to the nature of $\mathrm{Mg}$ corrosion. This issue might cause swollen feeling at implanted area. Fortunately, swollen feeling can be minimized by subcutaneous puncture procedure (to leak the hydrogen cavity). 


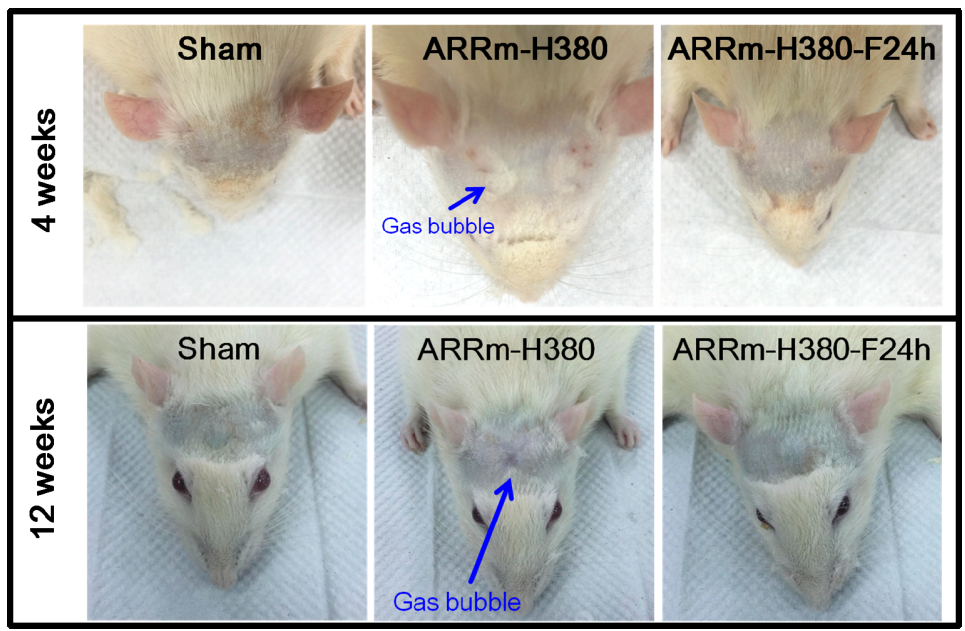

Figure 11. Hydrogen gas cavity and allergy observation.

As shown in Figure 12, the difference in degradation between ARRm-H380 and ARRm-H380-F24 $\mathrm{h}$ lies in the corrosion behavior. Whereas the ARRm-H380 sample showed a homogenous corrosion morphology, resulting in an evenly corroded cross-section, the ARRm-H380-F24 h specimen showed a localized corrosion morphology due to the corrosive factors penetrating into the substrate at the weak points in the fluoride coating [29]. Therefore, the weak points corroded first, after which they evolved into localized corrosion pits and/or holes. Furthermore, the thickness and weight retention of the degraded ARRm-H380-F24 h was significantly thicker and heavier than the degraded ARRm-H380, which means that the degradation and amount of released $\mathrm{Mg}$ ions of ARRm-H380-F24 h were relatively lower than for ARRm-H380.

(a)

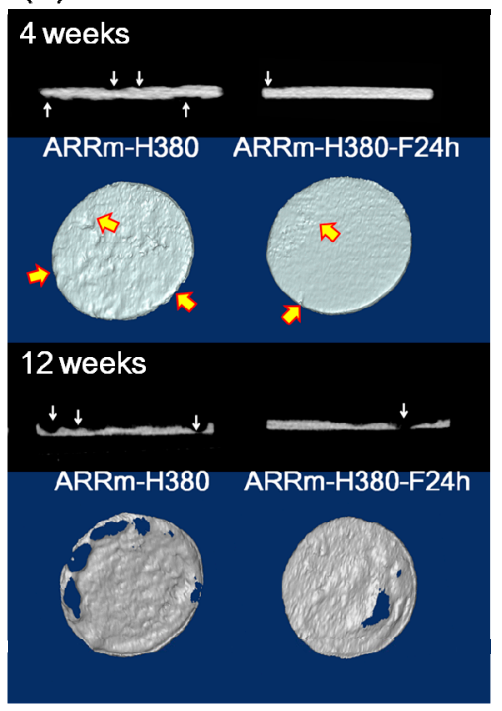

(b)

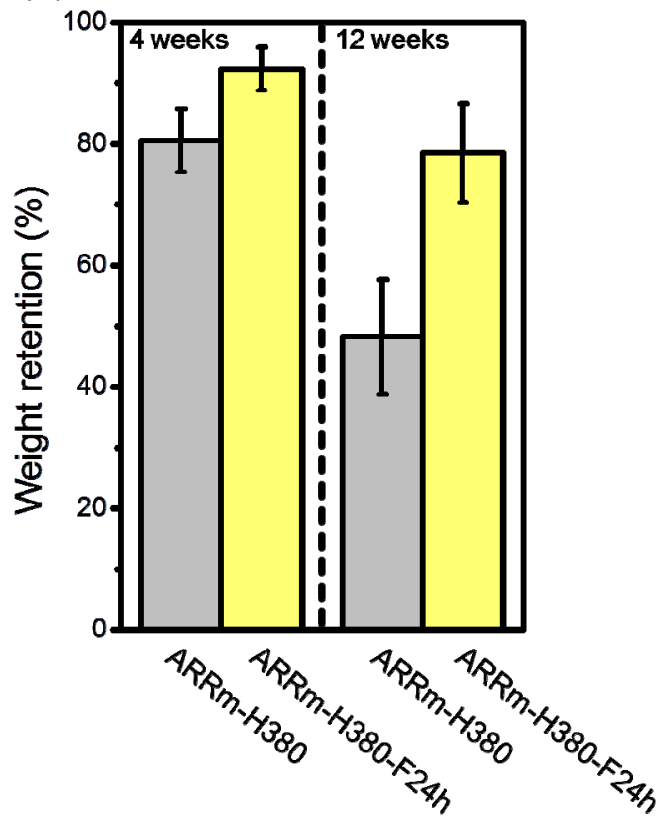

Figure 12. (a) $3 \mathrm{D}$ images of implanted Mg samples; (b) weight retention calculated from CT data. (arrow: the location of initial corrosion pit).

Figure 13 presents the 3D reconstruction images derived from the $\mu-\mathrm{CT}$ analysis. The sham group showed no significant new bone regeneration; a bone fracture of the $5 \mathrm{~mm}$ size-level defect can not 
be healed because the rat cranial bone lacks blood supply and muscle tissue. However, a remarkable new bone-regeneration phenomenon can be observed in the ARRm-H380 group after 4 weeks and 12 weeks implantation. In comparison, the ARRm-H380-F24 h group showed relatively lower new bone-regeneration capability than with ARRm-H380.

(a)

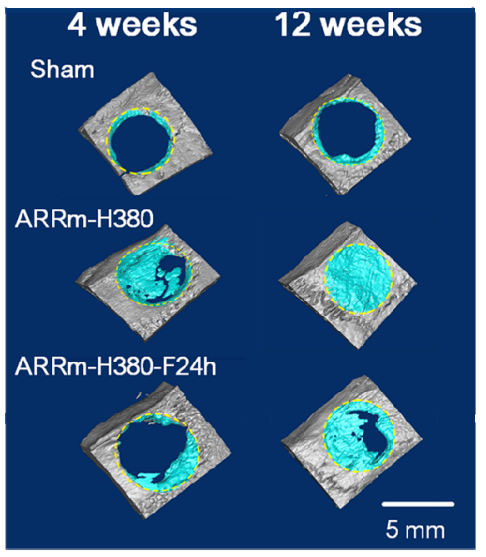

(b) 4 weeks

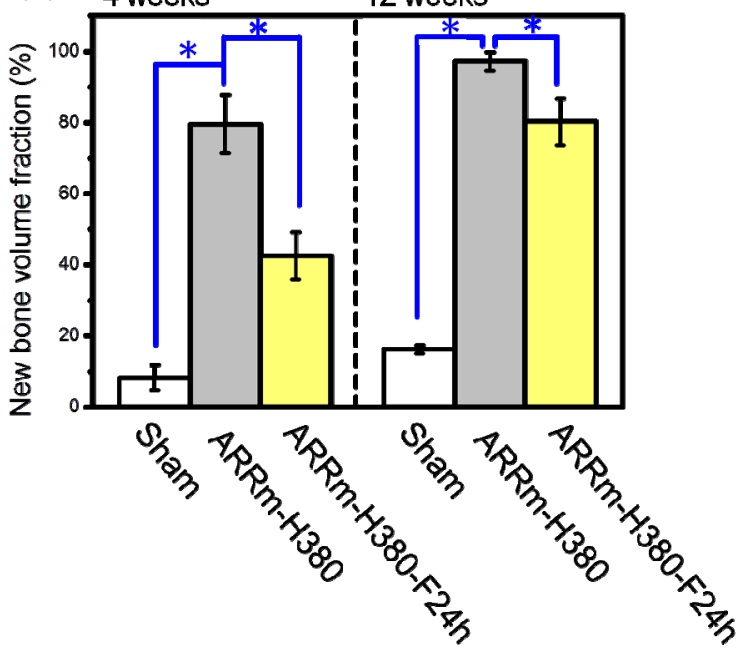

Figure 13. (a) 3D images of CSD sites of different experimental groups; (b) new bone volume fraction calculated from CT data. (Data presented as mean $\pm \mathrm{SD}, n=4$ and analyzed using a one-way ANOVA, * $p<0.05)$.

Interestingly, in comparing Figures 12 and 13, it appears that a higher degradation amount of $\mathrm{Mg}$ substrate leads to superior bone regeneration ability. Hence, our results indicate that $\mathrm{Mg}$ ions act as an effective factor for bone growth. Moreover, with respect to the statistical data (Figure 13b), it seems clear that the bone-regenerative capability of the $\mathrm{Mg}$-based regeneration membrane accelerated bone tissue formation. The new bone volume fraction with the ARRm-H380 membrane approached almost 100\% after 12 weeks implantation. Previous reports have verified that $\mathrm{Mg}$ ions act as a stimulator to enhance cell proliferation and migration, and that the functional biochemical stimulation of $\mathrm{Mg}$ ions can improve wound healing in vitro and in vivo [7,30]. To the best of our knowledge, this report is the first to discover that $\mathrm{Mg}$-based materials are capable of being applied in dentistry with excellent outcomes. This suitability could be attributed to the excellent mechanical structuring function and appropriate degradation properties of modified ECO505 (especially ARRm-H380 and ARRm-H380-F24 h).

In this study, we demonstrated the first report of the promoting effect for bone healing of the cranial bone in SD rats using modified ECO505 magnesium alloy to acquire the proper magnesium releasing concentration for bone tissue regeneration. According to the referenced articles and the study reported here, we created a representative illustration to demonstrate the promoting mechanism (see Figure 14). These results verified that the ARRm-H380 possessed a proper Mg-releasing ability to stimulate and enhance the regeneration of the bone defect areas, which is one of the key success factors for a GBR material. Although ARRm-H380-F24 h showed relatively lower bone-regeneration ability, its delayed degradation characterization can be effectively applied in older patients who generally require more recovery time. Therefore, this research successfully provides two future therapy solutions for different patients or therapy demands, namely short implantation period with ultra-fast healing effect, and long implantation period with moderate healing effect. 


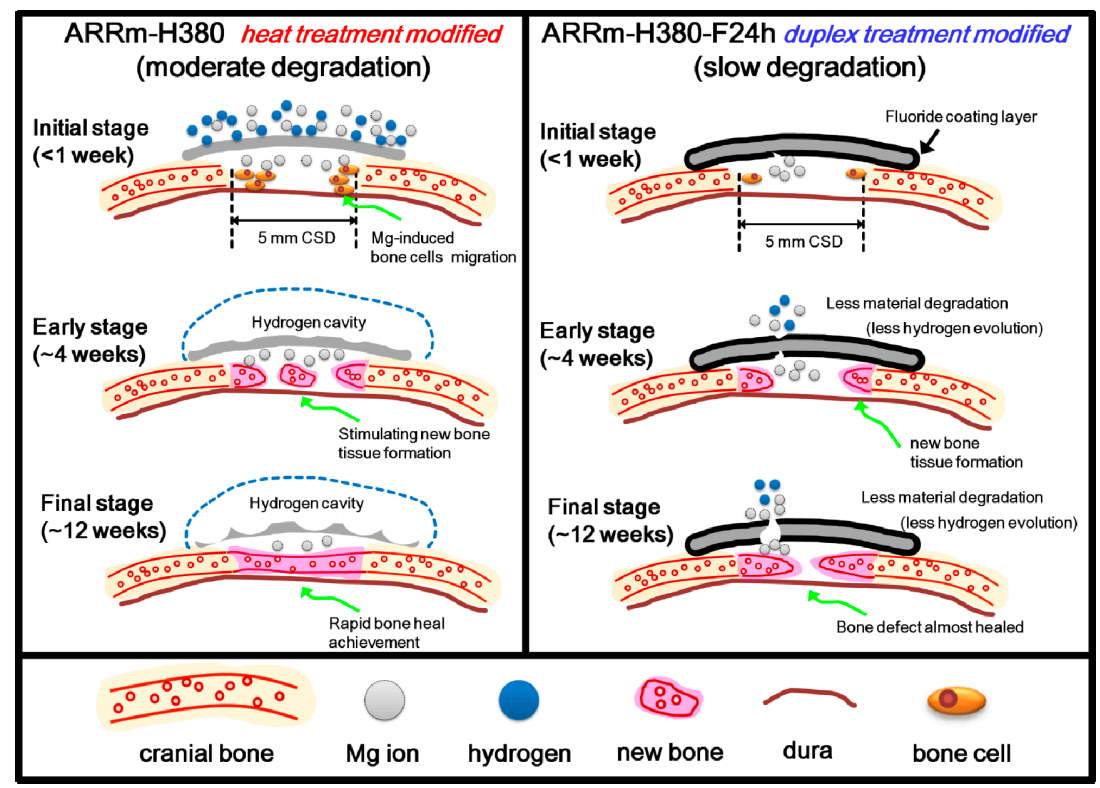

Figure 14. Schematic representation of $\mathrm{Mg}$-based regeneration membrane degradation and new bone regeneration characteristics.

\section{Conclusions}

1. The environmentally friendly ECO505 material was successfully developed as the raw material of a novel Mg-based regeneration membrane.

2. The H380 solid-solution treatment could lead to the recovery of the matrix, refinement and reduction of the $\mathrm{MgZn}_{2}$ secondary phases while enhancing elongation. Optimization of the solid-solution heat treatment requires the precisely controlled condition of $380{ }^{\circ} \mathrm{C} \_2 \mathrm{~h}$ to prevent excessive grain growth in the ARRm material, resulting in ultimate elongation $(20.2 \%)$. The mechanical properties of the coarse-grained microstructure (ARRm- $3800^{\circ} \mathrm{C} \_4 \mathrm{~h}$ and ARRm-380 ${ }^{\circ} \mathrm{C}_{-} 10 \mathrm{~h}$ ) are not reliable for practical application.

3. ARRm-H380 can form a better fluoride coating quality on substrates than non-heat-treated ARRm substrate, thereby showing a higher gain of PE value (93.8\%) and corrosion resistance $\left(56 \mathrm{k} \Omega \cdot \mathrm{cm}^{2}\right)$.

4. ARRm-H380 and ARRm-H380-F24 h specimens can effectively enhance corrosion resistance and minimize the effects of stress corrosion and crevice corrosion, and so constitutes promising candidates for regeneration membrane treatment.

5. ARRm-H380 had a significant positive influence on new bone regeneration, where the CSD could heal almost $100 \%$ after 12 weeks implantation. In addition, although ARRm-H380-F24 h showed relatively lower bone regeneration ability, it nevertheless exhibited better long-term corrosion resistance than ARRm-H380.

Acknowledgments: The authors are grateful to the Instrument Center of National Cheng Kung University and Southern Taiwan Medical Device Industry Cluster, AZ-10-16-35-105, for their financial support of this research.

Author Contributions: Da-Jun Lin conceived and designed the experiments; Da-Jun Lin and Hung-Pang Lee performed the experiments; Da-Jun Lin and Fei-Yi Hung analyzed the data; Fei-Yi Hung and Ming-Long Yeh contributed reagents/materials/analysis tools; Da-Jun Lin wrote the paper.

Conflicts of Interest: The authors declare no conflict of interest. 


\section{References}

1. Bottino, M.C.; Thomas, V.; Schmidt, G.; Vohra, Y.K.; Chu, T.M.G.; Kowolik, M.J.; Janowski, G.M. Recent advances in the development of GTR/GBR membranes for periodontal regeneration-A materials perspective. Dent. Mater. 2012, 28, 703-721. [CrossRef] [PubMed]

2. Mealey, B.L. Periodontal disease and diabetes-A two-way street. J. Am. Dent. Assoc. 2006, 137, S26-S31. [CrossRef]

3. Page, R.C.; Altman, L.C.; Ebersole, J.L.; Vandesteen, G.E.; Dahlberg, W.H.; Williams, B.L.; Osterberg, S.K. Rapidly progressive periodontitis-A distinct clinical condition. J. Periodontol. 1983, 54, 197-209. [CrossRef] [PubMed]

4. Yoshikawa, G.; Murashima, Y.; Wadachi, R.; Sawada, N.; Suda, H. Guided bone regeneration (GBR) using membranes and calcium sulphate after apicectomy: A comparative histomorphometrical study. Int. Endod. J. 2002, 35, 255-263. [CrossRef] [PubMed]

5. Rakhmatia, Y.D.; Ayukawa, Y.; Furuhashi, A.; Koyano, K. Current barrier membranes: Titanium mesh and other membranes for guided bone regeneration in dental applications. J. Prosthodont. Res. 2013, 57, 3-14. [CrossRef] [PubMed]

6. Witte, F.; Hort, N.; Vogt, C.; Cohen, S.; Kainer, K.U.; Willumeit, R.; Feyerabend, F. Degradable biomaterials based on magnesium corrosion. Curr. Opin. Solid State Mater. Sci. 2008, 12, 63-72. [CrossRef]

7. Lin, D.J.; Hung, F.Y.; Yeh, M.L.; Lui, T.S. Microstructure-modified biodegradable magnesium alloy for promoting cytocompatibility and wound healing in vitro. J. Mater. Sci. Mater. Med. 2015, 26, 1-10. [CrossRef] [PubMed]

8. Lin, D.J.; Hung, F.Y.; Yeh, M.L.; Lee, H.P.; Lui, T.S. Development of a novel micro-textured surface using duplex surface modification for biomedical Mg alloy applications. Mater. Lett. 2017, 206, 9-12. [CrossRef]

9. Xin, Y.; Hu, T.; Chu, P.K. In vitro studies of biomedical magnesium alloys in a simulated physiological environment: A review. Acta Biomater. 2011, 7, 1452-1459. [CrossRef] [PubMed]

10. Lin, D.J.; Hung, F.Y.; Jakfar, S.; Yeh, M.L. Tailored coating chemistry and interfacial properties for construction of bioactive ceramic coatings on magnesium biomaterial. Mater. Des. 2016, 89, 235-244. [CrossRef]

11. Cai, S.H.; Lei, T.; Li, N.F.; Feng, F.F. Effects of Zn on microstructure, mechanical properties and corrosion behavior of Mg-Zn alloys. Mater. Sci. Eng. C 2012, 32, 2570-2577. [CrossRef]

12. Song, Y.W.; Han, E.H.; Shan, D.Y.; Yim, C.D.; You, B.S. The role of second phases in the corrosion behavior of Mg-5Zn alloy. Corros. Sci. 2012, 60, 238-245. [CrossRef]

13. Lin, D.J.; Hung, F.Y.; Lui, T.S.; Yeh, M.L. Heat treatment mechanism and biodegradable characteristics of ZAX1330 mg alloy. Mater. Sci. Eng. C 2015, 51, 300-308. [CrossRef] [PubMed]

14. Yan, T.T.; Tan, L.L.; Xiong, D.S.; Liu, X.J.; Zhang, B.C.; Yang, K. Fluoride treatment and in vitro corrosion behavior of an AZ31B magnesium alloy. Mater. Sci. Eng. C 2010, 30, 740-748. [CrossRef]

15. Bakhsheshi-Rad, H.R.; Idris, M.H.; Kadir, M.R.A.; Daroonparvar, M. Effect of fluoride treatment on corrosion behavior of Mg-Ca binary alloy for implant application. Trans. Nonferr. Met. Soc. China 2013, 23, 699-710. [CrossRef]

16. Lin, D.J.; Hung, F.Y.; Liu, H.J.; Yeh, M.L. Dynamic corrosion and material characteristics of $\mathrm{Mg}-\mathrm{Zn}-\mathrm{Zr}$ mini-tubes: The influence of microstructures and extrusion parameters. Adv. Eng. Mater. 2017. [CrossRef]

17. Li, Z.; Shizhao, S.; Chen, M.; Fahlman, B.D.; Debao, L.; Bi, H. In vitro and in vivo corrosion, mechanical properties and biocompatibility evaluation of MgF2-coated $\mathrm{Mg}-\mathrm{Zn}-\mathrm{Zr}$ alloy as cancellous screws. Mater. Sci. Eng. C 2017, 75, 1268-1280. [CrossRef] [PubMed]

18. Ramakrishnan, S.; Koltun, P. Global warming impact of the magnesium produced in china using the pidgeon process. Resour. Conserv. Recycl. 2004, 42, 49-64. [CrossRef]

19. Ha, W.; Kim, Y.J. Effects of cover gases on melt protection of Mg alloys. J. Alloy. Compd. 2006, 422, $208-213$. [CrossRef]

20. Lin, D.J.; Hung, F.Y.; Yeh, M.L.; Lee, H.P.; Lui, T.S. Correlation between anti-corrosion performance and optical reflectance of nano fluoride film on biodegradable $\mathrm{Mg}-\mathrm{Zn}-\mathrm{Zr}$ alloy: A non-destructive evaluation approach. Int. J. Electrochem. Sci. 2017, 12, 3614-3634. [CrossRef]

21. Prasad, Y.V.R.K.; Rao, K.P. Effect of homogenization on the hot deformation behavior of cast AZ31 magnesium alloy. Mater. Des. 2009, 30, 3723-3730. [CrossRef] 
22. Watanabe, H.; Mukai, T.; Ishikawa, K.; Higashi, K. Low temperature superplasticity of a fine-grained ZK60 magnesium alloy processed by equal-channel-angular extrusion. Scr. Mater. 2002, 46, 851-856. [CrossRef]

23. Stern, M.; Geary, A.L. Electrochemical polarization-1. A theoretical analysis of the shape of polarization curves. J. Electrochem. Soc. 1956, 103, C205.

24. Chang, J.W.; Guo, X.W.; Fu, P.H.; Peng, L.M.; Ding, W.J. Effect of heat treatment on corrosion and electrochemical behaviour of Mg-3Nd-0.2Zn-0.4Zr (wt. \%) alloy. Electrochim. Acta 2007, 52, 3160-3167. [CrossRef]

25. Lee, H.P.; Lin, D.J.; Yeh, M.L. Phenolic modified ceramic coating on biodegradable Mg alloy: The improved corrosion resistance and osteoblast-like cell activity. Materials 2017, 10. [CrossRef] [PubMed]

26. Winzer, N.; Atrens, A.; Song, G.L.; Ghali, E.; Dietzel, W.; Kainer, K.U.; Hort, N.; Blawert, C. A critical review of the stress corrosion cracking (SCC) of magnesium alloys. Adv. Eng. Mater. 2005, 7, 659-693. [CrossRef]

27. Ghali, E.; Dietzel, W.; Kainer, K.U. Testing of general and localized corrosion of magnesium alloys: A critical review. J. Mater. Eng. Perform. 2004, 13, 517-529. [CrossRef]

28. Song, D.; Li, C.; Zhang, L.; Ma, X.; Guo, G.; Zhang, F.; Jiang, J.; Ma, A. Decreasing bio-degradation rate of the hydrothermal-synthesizing coated Mg alloy via pre-solid-solution treatment. Materials 2017, 10. [CrossRef] [PubMed]

29. Witte, F.; Fischer, J.; Nellesen, J.; Vogt, C.; Vogt, J.; Donath, T.; Beckmann, F. In vivo corrosion and corrosion protection of magnesium alloy LAE442. Acta Biomater. 2010, 6, 1792-1799. [CrossRef] [PubMed]

30. Schaller, B.; Saulacic, N.; Imwinkelried, T.; Beck, S.; Liu, E.W.Y.; Gralla, J.; Nakahara, K.; Hofstetter, W.; Iizuka, T. In vivo degradation of magnesium plate/screw osteosynthesis implant systems: Soft and hard tissue response in a calvarial model in miniature pigs. J. Cranio-Maxillofac. Surg. 2016, 44, 309-317. [CrossRef] [PubMed]

(C) 2017 by the authors. Licensee MDPI, Basel, Switzerland. This article is an open access article distributed under the terms and conditions of the Creative Commons Attribution (CC BY) license (http://creativecommons.org/licenses/by/4.0/). 